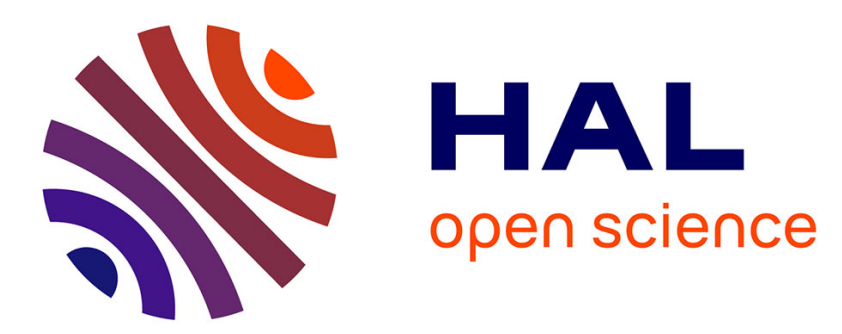

\title{
Survey on Some Automotive Semi-Active Suspension Control Methods: a Comparative Study on a Single-Corner Model
}

Charles Poussot-Vassal, Cristiano Spelta, Olivier Sename, Sergio M. Savaresi, Luc Dugard

\section{To cite this version:}

Charles Poussot-Vassal, Cristiano Spelta, Olivier Sename, Sergio M. Savaresi, Luc Dugard. Survey on Some Automotive Semi-Active Suspension Control Methods: a Comparative Study on a SingleCorner Model. IFAC WC 2011 - 18th IFAC World Congress, Aug 2011, Milan, Italy. pp.1802-1807. hal-00681432

\section{HAL Id: hal-00681432 \\ https://hal.science/hal-00681432}

Submitted on 21 Mar 2012

HAL is a multi-disciplinary open access archive for the deposit and dissemination of scientific research documents, whether they are published or not. The documents may come from teaching and research institutions in France or abroad, or from public or private research centers.
L'archive ouverte pluridisciplinaire HAL, est destinée au dépôt et à la diffusion de documents scientifiques de niveau recherche, publiés ou non, émanant des établissements d'enseignement et de recherche français ou étrangers, des laboratoires publics ou privés. 


\title{
Survey on Some Automotive Semi-Active Suspension Control Methods: a Comparative Study on a Single-Corner Model
}

\author{
C. Poussot-Vassal ${ }^{*}$ C. Spelta ${ }^{* *}$ O. Sename ${ }^{* * *}$ \\ S.M. Savaresi ${ }^{* * *}$ L. Dugard ${ }^{* * *}$ \\ * ONERA Systems Control 6 Flight Dynamics dpt., Toulouse, France. \\ ** Dipartimento di Ingegneria dell'Informazione e Metodi Matematici, \\ Università degli Studi di Bergamo, Italy \\ *** GIPSA-lab Control Systems department, Grenoble, France. \\ **** Dipartimento di Elett. e Informazione, Politecnico di Milano, \\ Italy.
}

\begin{abstract}
In this paper, we propose an overview and a benchmark of the most classic semi-active suspension control laws. Based on a recent result where the optimal semi-active performance trade-off was derived (see Poussot-Vassal et al. (2010)), here, a complete benchmark to evaluate the main semi-active suspension control design methods is proposed. The present paper gives a quick picture of the present state of the art in the semi-active suspension control field in terms of comfort and road-holding trade-off.
\end{abstract}

Keywords: Semi-active suspension, Nonlinear control, LPV control, Performance evaluation, Benchmark.

\section{INTRODUCTION}

In the automotive field, semi-active suspensions have received a lot of attention since they seem to provide the best compromise between cost (energy-consumption, actuators/sensors hardware) and performance. The research in this field follows two mainstreams: the study of new technologies of semi-active actuation of damping (like electro-hydraulic, electro-rheological and magnetorheological damper), and the design of semi-active control strategies (see e.g. Karnopp et al. (1974); Tseng and Hedrick (1994); Hrovat (1997); Kawabe et al. (1998); Ahmadian and Reichert (2001); Guardabassi and Savaresi (2001); Hong et al. (2002); Giua et al. (2004); Geurts et al. (2006); Giorgetti et al. (2006a); Canale et al. (2006); Savaresi and Spelta (2009) and references therein).

In a previous work, Poussot-Vassal et al. (2010) proposed a methodology to evaluate the best performance trade-off, in term of comfort and road-holding, a semi-active suspension system can achieve. Based on this recent development, the main contribution of this paper is to provide a full analysis and benchmark of some of the most common and dedicated semi-active suspension control law performances, both for the comfort and for the road-holding objectives.

This work is carried out on the basis of the well known single-corner vehicle model including a semi-active suspension system (see Figure 1). Performances are then thoroughly evaluated trough dedicated frequency domain simulations.

The paper is organized as follows: Section 2 presents the semi-active suspension models and recalls the performance criteria used in Savaresi et al. (2010). In Section 3 and
4, some classical dedicated semi-active control approach for comfort and road-holding performance enhancement are recalled. More generic or complex control algorithms are given in Section 5. All the proposed algorithms are evaluated with numerical simulations and compared to the optimal and passive performances (obtained in PoussotVassal et al. (2010)), using both frequency responses and performance index, providing then a(n almost) complete semi-active suspension control benchmark. Conclusions are gathered in Section 7.

\section{SINGLE-CORNER MODEL AND PERFORMANCE DEFINITIONS}

\subsection{Single-corner model}

The single-corner car model is the basic model used for suspension analysis. It consists in double mass / spring / damper system describing the dynamics of the chassis and the center of the wheel. The suspension system is modeled by a spring and a damping system, and the tire is often reduced to a spring element. Figure 1 illustrates this singlecorner model, defined through relation (1).

$$
\left\{\begin{aligned}
M \ddot{z}= & -k\left(z-z_{t}-\Delta_{s}\right)-c\left(\dot{z}-\dot{z}_{t}\right)-M g \\
m \ddot{z}_{t}= & k\left(z-z_{t}-\Delta_{s}\right)+c\left(\dot{z}-\dot{z}_{t}\right) \\
& -k_{t}\left(z_{t}-z_{r}-\Delta_{t}\right)-m g \\
\dot{c}= & -\beta\left(c-c_{i n}\right) \\
z_{t}-z_{r}< & \Delta_{t}
\end{aligned}\right.
$$

where $z, z_{t}$, and $z_{r}$ are the vertical positions of the body, of the unsprung mass, and of the road profile respectively. $M$ is the single-corner body mass; $\mathrm{m}$ is the unsprung mass (tire, wheel, brake calliper, suspension links, etc.). 


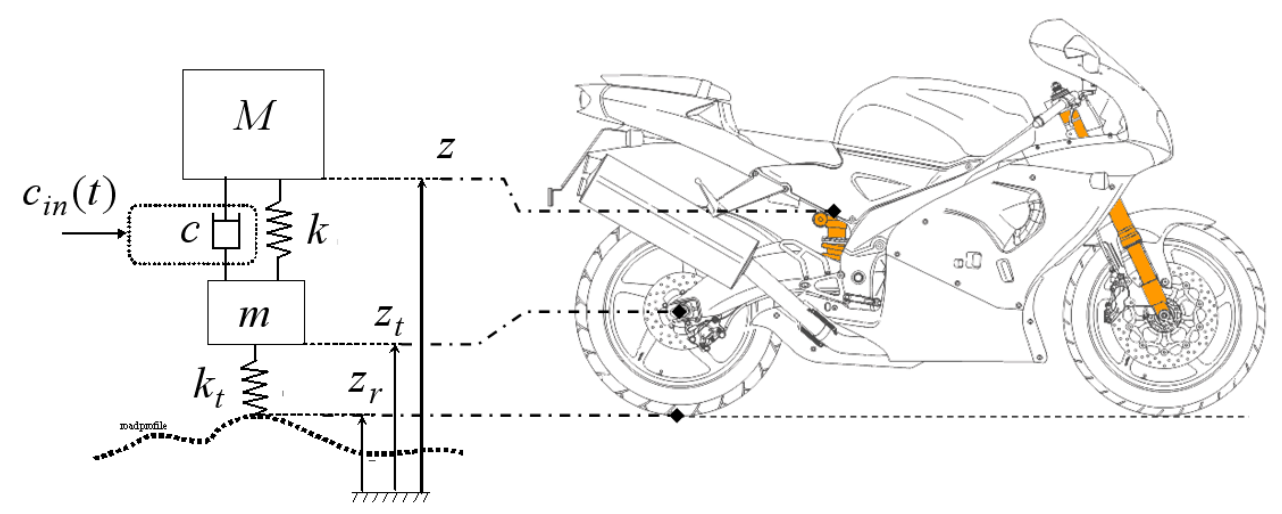

Fig. 1. Single-corner vehicle model.

$g$ is the gravitational constant. $k \in \mathbb{R}^{+}$and $k_{t} \in \mathbb{R}^{+}$ are the stiffness of the suspension spring and of the tire, respectively; $\Delta_{s} \in \mathbb{R}^{+}$and $\Delta_{t} \in \mathbb{R}^{+}$are the length of the unloaded suspension spring and tire, respectively. $c \in \mathbb{R}^{+}$and $c_{i n} \in \mathbb{R}^{+}$are the actual and the requested damping coefficients of the shock-absorber, respectively. The damping-coefficient variation is ruled by a 1st-order dynamic, where $\beta \in \mathbb{R}^{+}$is the bandwidth. The actual damping coefficient $c$ always remains in that interval: $c_{\min } \leq c \leq c_{\max }$, where $c_{\min } \in \mathbb{R}^{+}$and $c_{\max } \in \mathbb{R}^{+}$ are the shock-absorber technological limitations. This last inequality is the so-called "passivity-constraint" of a semiactive suspension - guaranteeing that the actuator only dissipates energy (see e.g. Savaresi and Spelta (2009); Savaresi et al. (2010)). Since the control signal $c_{i n}$ modifies the damping coefficient $c$, a state variable, model (1) is nonlinear. When a passive suspension is considered, (1) is reduced to a 4th-order linear system (by simply setting $\dot{c}=0$ and $c=$ constant - e.g. nominal damping).

For nonlinear control design, the following model is commonly used:

$$
\left\{\begin{aligned}
M \ddot{z} & =-k\left(z-z_{t}\right)-c\left(\dot{z}-\dot{z}_{t}\right) \\
m \ddot{z}_{t} & =k\left(z-z_{t}\right)+c\left(\dot{z}-\dot{z}_{t}\right)-k_{t}\left(z_{t}-z_{r}\right) \\
\dot{c} & =\beta\left(c_{i n}-c\right)
\end{aligned}\right.
$$

Similarly, in order to apply linear control techniques, a linear-like semi-active suspension model is (commonly) defined as follows:

$$
\left\{\begin{aligned}
M \ddot{z} & =-k\left(z-z_{t}\right)-c^{0}\left(\dot{z}-\dot{z}_{t}\right)-F_{d} \\
m \ddot{z}_{t} & =k\left(z-z_{t}\right)+c^{0}\left(\dot{z}-\dot{z}_{t}\right)-k_{t}\left(z_{t}-z_{r}\right)+F_{d} \\
\dot{F}_{d} & =-\beta\left(F_{d}-u\right)
\end{aligned}\right.
$$

With reference to models (1) and (2), the linearised model (3) includes symbols with the following meaning: $c^{0}$ denotes the nominal damping (which can be used as a design parameter when synthesizing the controller); $F_{d}$ is an additional damping force commanded by the control variable $u$, according to a 1st order actuation dynamic.

In order to be fully equivalent to (1) and (2), the control signal $u$ should respect the passivity-constraint. In models (1) and (2) this constraint is described as $c_{\min } \leq c_{i n} \leq$ $c_{\max }$. It is straightforward to see that in model (3) this constraint is recast as follows: the additional force reference $u$ should satisfies $u \in \mathcal{D}\left(c_{\min }, c_{\max }, c^{0}\right) \subseteq \mathbb{R}$, where the dissipative $\mathcal{D}\left(c_{\min }, c_{\max }, c^{0}\right)$ set is defined as follows (see Figure 2):

$$
\left\{\begin{array}{c}
\forall(U, V) \in \mathbb{R} \times \mathbb{R} \mid \\
\left(U-\left(c_{\max }-c^{0}\right) V\right)\left(\left(c_{\min }-c^{0}\right) V-U\right) \geq 0
\end{array}\right\}
$$

where $c_{\min }$ and $c_{\max }$ are the minimal and maximal damping factors of the considered controlled damper, normalized around $c^{0} \in \mathbb{R}^{+}$. Note that in formulation (3) of the single-corner model, the system with no control $(u=0)$ is damped thanks to $c^{0}$ (hence stable and damped). This remark is practically important for numerical reasons when some control approaches (such as LMI-based, MPC, ... ) are applied.

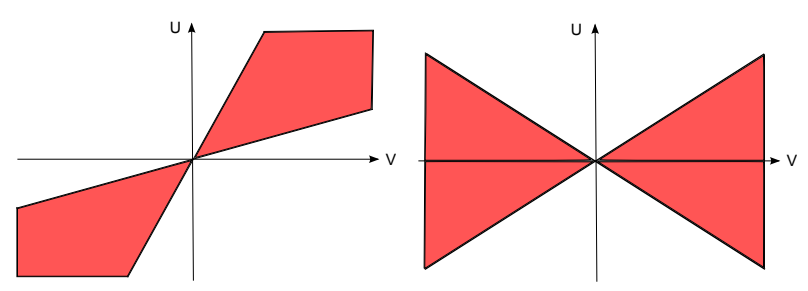

Fig. 2. Illustration of the dissipative $\mathcal{D}\left(c_{\min }, c_{\max }, c^{0}\right)$ set as a function of $c^{0}$. Left: $c^{0}=0$, right: $c^{0}=\frac{c_{\min }+c_{\max }}{2}$.

\subsection{Performance indexes definition}

Since the paper aims at evaluating the trade-off of the semi-active suspension laws in terms of comfort and roadholding, the performance metric proposed in PoussotVassal et al. (2010) is used here. This criteria focuses on two specific signals, representing either the comfort or the road-holding performance (for further detail, refer to Hrovat (1997); Kiencke and Nielsen (2000) and book of the authors Savaresi et al. (2010)), namely:

- The vertical chassis acceleration $\ddot{z}$ (or displacement $z$ ) response to road disturbances $z_{r}$, between 0 and $20 \mathrm{~Hz}$, representing the acceleration felt by the driver, i.e. the comfort specification.

- The vertical wheel deflection $z_{t}-z_{r}$ response to road disturbances $z_{r}$, between 0 and $30 \mathrm{~Hz}$, representing the ability of the wheel to stay in contact with the road, i.e. the road-holding specification.

The common objective is then to minimize either the transfer $z_{r}$ to $\ddot{z}$ - identically $z$ - (comfort) or the transfer $z_{r}$ to $z_{t}-z_{r}$ (road-holding) or a combination of these two transfer. More formally, let define the function $\mathcal{C}$ : 
$\mathbb{R} \times \mathbb{R} \times \mathbb{R} \rightarrow \mathbb{R}$, as $\mathcal{C}(x, \underline{f}, \bar{f})=\int_{f}^{\bar{f}}|x(f)|^{2} d f$, where $x(f)$ represents the frequency dependent signal of interest, obtained by a nonlinear frequency response algorithm (similar to the one given in Savaresi et al. (2010); PoussotVassal et al. (2010)); $f$ and $\bar{f}$ represent the interval limits of interest. Then, the comfort and road-holding criteria are respectively defined as:

- $J_{z}$, Comfort criteria:

$$
J_{z}=\frac{\mathcal{C}\left(F_{z}, 0,20\right)}{\mathcal{C}\left(F_{z}^{\text {nom }}, 0,20\right)}
$$

- $J_{z_{\text {deft }}}$, Road-holding criteria:

$$
J_{z_{\text {deft }}}=\frac{\mathcal{C}\left(F_{z_{\text {deft }}}, 0,30\right)}{\mathcal{C}\left(F_{z_{\text {def }} \text { nom }}, 0,30\right)}
$$

where $F_{z}$ and $F_{z_{d e f t}}$ are the frequency responses of the controlled suspension; while $F_{z}^{\text {nom }}$ and $F_{z_{d e f_{t}}}^{\text {nom }}$ are the frequency responses of the passive uncontrolled reference suspension system with a nominal damping $c=1500 \mathrm{Nm} / \mathrm{s}$ (i.e. model (1) with $c=1500$ and $c_{i n}=1500$ ).

\section{COMFORT-ORIENTED SEMI-ACTIVE SUSPENSION CONTROL}

This section focusses on the main comfort-oriented dedicated semi-active suspension control strategies. This section gathers, in an increasing complexity order, the main semi-active control laws for comfort objective.

\subsection{Skyhook two-state damper control (SH-2)}

The two-state Skyhook control is an on/off strategy that switches between high and low damping coefficients in order to achieve body comfort specifications. This control law is recalled as follows.

Proposition 1. (SH-2 states control). Given system (2), the SH-2 law is defined as:

$$
c_{i n}= \begin{cases}c_{\min } & \text { if } \dot{z} \dot{z}_{\text {def }} \leq 0 \\ c_{\max } & \text { if } \dot{z} \dot{z}_{\text {def }}>0\end{cases}
$$

Basically, this control law consists in a switching controller which deactivates the controlled damper when the body speed and suspension deflection speed have opposite signs. The controlled damper technology only needs to have two damping coefficient states. This control strategy presents the advantage to be simple but requires two sensors.

Many studies have concerned the Skyhook control strategy since it represents a simple but efficient way to achieve good comfort requirement (see e.g. Simon (2001); Ahmadian et al. (2004)). Some extended versions of the Skyhook control have been also developed, such as the adaptive one in Song et al. (2007) or the gain-scheduled one in Hong et al. (2002).

\subsection{Skyhook linear approximation damper control $(S H-L)$}

An improved version of Skyhook control has been used to handle variable damping, either with discrete damping coefficients, or with continuously variable damper, as illustrated in Sohn et al. (2000); Sammier et al. (2003). The linear approximation of the Skyhook control algorithm, adapted to semi-active suspension actuators, is given as:
Proposition 2. (SH-L). Given system (2), the SH-L law is defined as:

$$
c_{i n}= \begin{cases}c_{\min } & \text { if } \dot{z} \dot{z}_{d e f} \leq 0 \\ \operatorname{sat}\left(\frac{\alpha c_{\max } \dot{z}_{d e f}+(1-\alpha) c_{\max } \dot{z}}{\dot{z}_{\text {def }}}\right) & \text { if } \dot{z} \dot{z}_{\text {def }}>0\end{cases}
$$

where $\alpha \in[0 ; 1]$ is a tuning parameter that modifies the closed-loop performances and sat denotes that $c_{\text {in }} \in$ $\left[c_{\min } ; c_{\max }\right]$.

When $\alpha=1$, this control law is equivalent to the Skyhook two-state one. As the two-state control, the linear approximation consists in a switching controller which modifies the damping factor according to the body speed and suspension deflection speed. The innovation rely in the fact that, according to the second expression (when $\dot{z} \dot{z}_{\text {def }}>0$ ), such a control provides an infinite number of damping coefficients. As a matter of fact, this control law requires a continuously variable controlled damper (e.g. an MR dampers). From the computational point of view, this control law also requires two measurements and is simple to implement, but suffers of $\dot{z}_{\text {def }}$ zero crossing as well (which is practically complex to measure).

\subsection{Acceleration Driven Damper control (ADD)}

The ADD control is a semi-active control law described in Savaresi et al. (2005), which consists in changing the damping factor using the acceleration knowledge.

Proposition 3. (ADD). Given system (2), the ADD law is defined as:

$$
c_{\text {in }}= \begin{cases}c_{\text {min }} & \text { if } \ddot{z} \dot{z}_{\text {def }} \leq 0 \\ c_{\text {max }} & \text { if } \ddot{z} \dot{z}_{\text {def }}>0\end{cases}
$$

This strategy shows to be optimal in the sense that it minimizes the vertical body acceleration when no road information is available. Since it requires the same number of sensors as the Skyhook two-state and the linear approximations control law, this control law is simple from the implementation point of view. Note that the control law is very similar to the two-state approximation of the Skyhook algorithm, with the difference that the switching law depends on the body acceleration $(\ddot{z})$, instead of the body speed (which is easier to practically measure). It is also to note that the ADD design is well adapted to comfort improvement but not to road-holding. Nevertheless, as the previous approach, the "switching dynamic" may influences the closed-loop performances, implying chattering effects.

\subsection{Power Driven Damper (PDD)}

In Morselli and Zanasi (2008), the authors propose a semiactive suspension control strategy using the port Hamiltonian techniques, which provide powerful tools for modeling mechatronics systems with dissipative components. Based on this observation, it is straightforward that this framework perfectly fits the semi-active suspension problem.

Proposition 4. (PDD). Given system (2), the PDD control approach is described by: 


$$
c_{i n}= \begin{cases}c_{\text {min }} & \text { if } k z_{\text {def }} \dot{z}_{\text {def }}+c_{\text {min }} \dot{z}_{\text {def }} \geq 0 \\ c_{\text {max }} & \text { if } k z_{\text {def }} \dot{z}_{\text {def }}+c_{\text {max }} \dot{z}_{\text {def }}<0 \\ \frac{c_{\text {min }}+c_{\text {max }}}{2} & \text { if } z_{\text {def }} \neq 0 \text { and } \dot{z}_{\text {def }}=0 \\ -\frac{k z_{\text {def }}}{\dot{z}_{\text {def }}} & \text { otherwise }\end{cases}
$$

where $k$ is the stiffness of the considered suspension.

In Morselli and Zanasi (2008) (see also Figures 3, 6 and 7), the authors show that this strategy provides results comparable to those of the ADD control law, while avoiding the chattering effect of the damping control value. The additional cost is the need for the knowledge of the spring stiffness $k$ and a more complex rule.

\subsection{Mixed Skyhook-Acceleration Driven Damper (SH-ADD)}

The Mixed Skyhook-ADD rational mixes the the best behaviour of SH and ADD, without an increasing of either the computational effort or the hardware complexity. The key idea exploits a very simple but effective frequency range selector, which is able to distinguish the instantaneous dynamical behaviour of the suspension: in the case of low frequency dynamics the SH is selected, while the ADD is selected otherwise. The resulting control law is incredibly simple and requires the same apparatus as $\mathrm{SH}$. Proposition 5. (SH-ADD). Given system (2), the mixed SH-ADD control approach is described by:

$$
c_{i n}=\left\{\begin{array}{ll}
c_{\text {max }} \text { if }\left[\left(\ddot{z}^{2}-\alpha^{2} \dot{z}^{2}\right) \leq 0 \text { AND } \dot{z} \dot{z}_{\text {def }}>0\right. \\
{\left[\left(\ddot{z}^{2}-\alpha^{2} \dot{z}^{2}\right)>0 \text { AND } \dot{z} \dot{z}_{\text {def }}>0\right.}
\end{array}\right] \text { OR }
$$

where $\alpha \in \mathbb{R}^{+}$is the tuning parameter allowing for frequency range selector, i.e. adjusts the "switch" between the $\mathrm{SH}$ and the ADD.

The amount $\left(\ddot{z}^{2}-\alpha^{2} \dot{z}^{2}\right)$ hence can be considered as a simple "frequency-range selector". The parameter $\alpha$ represents the frequency limit between the low and the high frequency ranges, and it is the only tuning knob of the control strategy (11). Specifically the value of $\alpha$ is set at the cross-over frequency (in $\mathrm{rad} / \mathrm{s}$ ) between $\mathrm{SH}$ and ADD. For a standard motorcycle suspension it has to be selected around 19rad/s (3Hz). A simplified version of this algorithm, employing one single sensor has also been developed, leading to very satisfactory results both in simulation and experimental benchmark (see Savaresi and Spelta (2009)).

\section{ROAD-HOLDING ORIENTED SEMI-ACTIVE SUSPENSION CONTROL}

Complementary to comfort-oriented control strategies, a very few studies have been devoted to the possible improvement of road-holding, using suspension actuator. Since few years, the studies on Global Chassis Control have emphasized that the suspension system may also help getting better road-holding and even handling, encouraging the community to reach this new objective.

\subsection{Ground-hook 2 states (GH-2)}

In a dual way to the Skyhook case, the 2-states Groundhook control (see Valasek et al. (1998)) consists in a switching control law depending now on the sign of the product between the suspension deflection velocity $\dot{z}_{\text {def }}$ and the velocity of the unsprung mass $\dot{z}_{t}$, as:

Proposition 6. (GH-2). Given system (2), the GH-2 control approach is:

$$
c_{i n}= \begin{cases}c_{\text {min }} & \text { if }-\dot{z}_{t} \dot{z}_{\text {def }} \leq 0 \\ c_{\text {max }} & \text { if }-\dot{z}_{t} \dot{z}_{\text {def }}>0\end{cases}
$$

This control has globally the same properties as the SH-2 one, but focussing around the unsprung mass.

\subsection{Ground-hook linear (GH-L)}

In this case, the semi-active damper allows to continuously change the damping coefficient, according to:

Proposition 7. (GH-L). Given system (2), the GH-L control approach is defined through:

$c_{i n}= \begin{cases}c_{\text {min }} & \text { if }-\dot{z}_{t} \dot{z}_{d e f} \leq 0 \\ \operatorname{sat}\left(\frac{\alpha c_{\max } \dot{z}_{d e f}+(1-\alpha) c_{\max } \dot{z}_{t}}{\dot{z}_{\text {def }}}\right) & \text { if }-\dot{z}_{t} \dot{z}_{\text {def }}>0\end{cases}$

where $\alpha \in[0 ; 1]$ is a tuning parameter that modifies the closed-loop performances and sat denotes that $c_{i n} \in$ $\left[c_{\min } ; c_{\max }\right]$.

\section{ADVANCED SEMI-ACTIVE SUSPENSION CONTROL}

Until now, the presented control approaches where completely dedicated to semi-active suspension systems and based on the nonlinear model (2). In this section we describe some of the main semi-active suspension control method, based on more classical (or usual) control tools, and relying on model (3).

\subsection{Clipped approaches}

Many works have concerned the application of classical control methods (e.g. $\mathcal{H}_{\infty}, \mathcal{H}_{2}$, pole placement, disturbance rejection, optimal, active Skyhook ...). However, most of the results were obtained for active suspensions, as in Zin et al. (2008). When applied to semi-active dampers, the dissipative constraint of the damper is usually handled using a simple projection (i.e. saturation, as shown in Figure 2). Even if it is not always referred to as the "clipped approach", the latter is very widespread in control strategies for semi-active suspension (see e.g. Karnopp (1983) and Margolis (1983)). In the control step, the force applied by the semi-active damper is then chosen to be as close as to the force required by the controller for a given suspension deflection speed and for the possible range of forces the damper can deliver. This simple strategy has been then applied in many cases (see e.g. Rossi and Lucente (2004); Du et al. (2005); Sename and Dugard (2003)).

The question that arises is: is optimal the clipped-optimal? If not, how far is it from the real optimal one? How would look like the optimal semi-active one? Clipped approaches lead to unpredictable behaviours and ensure neither closed-loop internal stability nor performances any longer. As a matter of fact, active control applied on 
a semi-active damper results in a "synthesize and try" method.

To cope with this last drawback, some modern control techniques have been applied to the specific semi-active suspension problem.

\subsection{Hybrid MPC control approaches}

In Giorgetti et al. (2006a), the authors introduce an hybrid model predictive optimal controller (using receding horizon). They solve an off-line optimization process which is a finite horizon optimal regulation problem s.t.:

$J^{*}(\xi, x(k))=\min _{\xi}\left[x^{T}(N) Q_{N} x(N)+\sum_{k=1}^{N-1} x^{T}(k) Q x(k)+y^{2}(k)\right]$

subject to,

$$
\left\{\begin{aligned}
x(k+1) & =A x(k)+B u(k) \\
y(k) & =C x(k)+D u(k) \\
0 & \leq u(k) \dot{z}_{\text {def }}(k) \\
|u(k)| & \leq \Lambda
\end{aligned}\right.
$$

where $Q$ is a performance index and $Q_{N}$ is the final weight, as in the optimal control theory. Matrices $A, B, C$ and $D$ in (15) define the LTI single-corner model (3), $\Lambda$ is the maximal force allowed by the considered controlled damper and $u(k) \dot{z}_{\text {def }}(k) \geq 0$ guarantees the passivity constraint. $\xi$ is a vector composed by the sequence of control signals (from 0 to $N-1$ ) to be applied, where, $N$ is the prediction horizon. Giorgetti et al. (2006a) show that choosing $N=1$ leads to performances that are identical to those of the clipped-optimal approach, and by increasing $N$ (e.g. until 40), the performances can be significantly improved. The implemented control law does not involve any optimization procedure since the control algorithm provides a collection of affine gains over a polyhedral partition of the system states $x$ (e.g. Borrelli et al. (2003)). By the way, this approach exhibits notable drawbacks, such as high complexity and switching between control regions and requires a complete full-state measurement.

\subsection{LPV semi-active control}

In an other philosophy, the "LPV semi-active" control adjustment, introduced in Poussot-Vassal et al. (2008), is a robust semi-active suspension control design using a Linear Parameter Varying (LPV) approach. More specifically, the proposed semi-active suspension control strategy is designed so that it minimizes the $\mathcal{H}_{\infty}$ performance criteria while guaranteeing the dissipative constraint thanks to a specific parameter dependent structure and a scheduling strategy design. The "LPV semi-active" controller design is summarized in the following algorithm (for $\mathcal{H}_{\infty}$ performances).

In this algorithm, $\rho$ is a parameter function of the type of semi-active actuator. It varies as a function of the deflection velocity and the required damping force (for more details refer to Poussot-Vassal et al. (2008); Savaresi et al. (2010)). The main interest of such approach is that it presents a large flexibility concerning the performances and the type and number of involved sensors. Additionally, it provides a robustness certificate thanks to the polytopic
Algorithm $1 \mathcal{H}_{\infty}$ "LPV semi-active"

(1) Based on initial system (3), and $\rho$-dependent performance weighting functions, construct the LPV polytopic system. Note that to complete this step, weighting filters should be defined and parametrized (refer to Poussot-Vassal et al. (2008) and Chapter 8 of Savaresi et al. (2010), for details).

(2) Compute the $\mathcal{H}_{\infty}$ LMI based "LPV semi-active" feasibility conditions.

(3) Reconstruct the LPV controller and obtain two dynamical full order controllers are obtained which are solution of the robust $\mathcal{H}_{\infty}$ "LPV semi-active" control problem.

$C(\underline{\rho})=\left[\begin{array}{cc}A_{c}(\underline{\rho}) & B_{c}(\underline{\rho}) \\ C_{c}(\underline{\rho}) & 0\end{array}\right]$ and $C(\bar{\rho})=\left[\begin{array}{cc}A_{c}(\bar{\rho}) & B_{c}(\bar{\rho}) \\ C_{c}(\bar{\rho}) & 0\end{array}\right]$

(4) Apply control law (where $\rho$ is varying):

$$
u=\left[\frac{|\rho-\bar{\rho}|}{\bar{\rho}-\underline{\rho}} C(\underline{\rho})+\frac{|\rho-\underline{\rho}|}{\bar{\rho}-\underline{\rho}} C(\bar{\rho})\right] z_{\text {def }}
$$

approach. The inherent counterpart of this flexibility is an important complexity in the design step.

\section{NUMERICAL SIMULATIONS}

In order to benchmark the performances of all these algorithms, the criteria presented in Savaresi et al. (2010) and recalled in Section 2 is applied. All simulation are carried out using a motorcycle parameter set (available in Poussot-Vassal et al. (2010) and Savaresi et al. (2010)). Note that in the following we do not simulate neither the Clipped approach (because of the nearly infinite way of adjusting) nor the MPC approach (complex to adjust due to multiple parameters, as well), but interested reader should refer to Tseng and Hedrick (1994); Giorgetti et al. (2006b).

\subsection{Frequency domain analysis}

First, we compare the frequency responses of $F_{z}$, the transfer between $z_{r}$ and $z$ (comfort), and $F_{z_{\text {deft }}}$, the transfer from $z_{r}$ to $z_{\text {deft }}=z_{t}-z_{r}$. On Figure 3 , the SH 2-states, SH linear (with $\alpha=0$ ), ADD and PDD are compared with the passive ones with either $c_{\min }$ or $c_{\max }$, illustrating to attenuate well the $F_{z}$ transfer while degrading the $F_{z_{\text {deft }}}$ one.

Similarly, Figure 4 compares the performance attenuation of the two road-holding control laws, namely, GH 2-states and GH linear (with $\alpha=0$ ) with the passive ones with either $c_{\min }$ or $c_{\max }$.

It clearly emphasizes the improvement on $F_{z_{\text {deft }}}$ while degrading the $F_{z}$ one. Moreover, it confirms the observation made in Morselli and Zanasi (2008) concerning the performances of the ADD and the PDD approaches. Finally, the Mixed SH-ADD (whith $\alpha$ adjusted to $20 \mathrm{~Hz}$ ) and "LPV semi-active" (with either a comfort or roadholding adjustment) frequency responses are compared to the passive cases on Figure 5.

On this last Figure, it is interesting to notice that the $\mathrm{SH}-$ ADD approach provides very good results in term of comfort performances. Concerning the LPV semi-active one, 

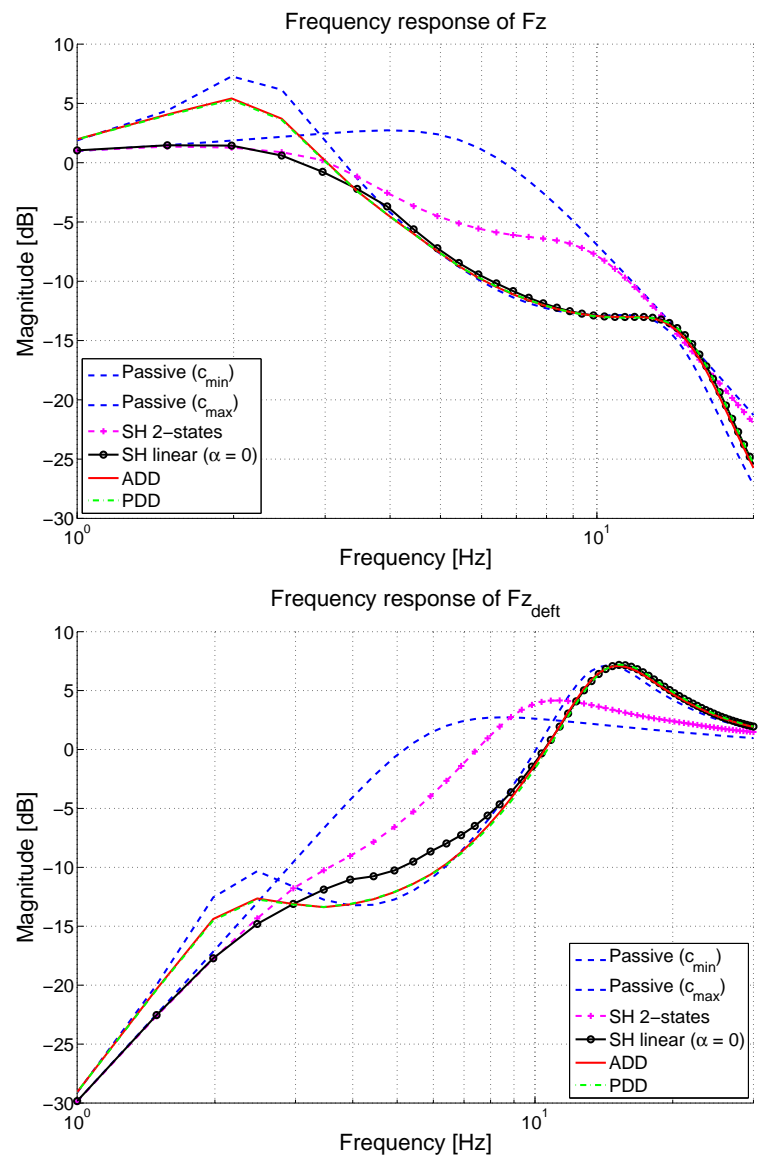

Fig. 3. Comfort oriented control law frequency response $F_{z}$ (top) and $F_{z_{d e f_{t}}}$ (bottom).

the two configurations tested shows the large flexibility of the approach. In the next subsection, all these approaches are gathered and compared to the passive and optimal performances, using the index defined in Section 2 .

\subsection{Performance indexes $\&$ trade-off analysis}

Since improvement in one criteria implies a deterioration on the other, the performance index introduced in Section 2 is also evaluated for each control strategy. On Figure 6, all the performance indexes are compared to the passive with three configurations: $c=\left\{c_{\min }, 1500, c_{\max }\right\}$ (note that $c=1500$ has been selected as the nominal reference value since it provides a nice compromise between comfort and road-holding).

In order to be even more precise, on Figure 7, the trade-off between comfort and road-holding is illustrated for all the previous strategies using a diagram with Comfort in the $\mathrm{x}$-axis and Road-holding in the $\mathrm{y}$-axis. This figure also includes the criteria evaluation for a passive suspension with damping varying from $c=100 \mathrm{~N} / \mathrm{m} / \mathrm{s}$ to $c=10000 \mathrm{~N} / \mathrm{m} / \mathrm{s}$ and the optimal bound numerically computed using the optimization framework presented in Poussot-Vassal et al. (2010).

The interesting point of this diagram is that (i) it illustrates the interest of the control to enhance the passive performances, (ii) shows the optimal performances of the $\mathrm{SH}-\mathrm{ADD}$ approach in term of comfort (blue cross close to
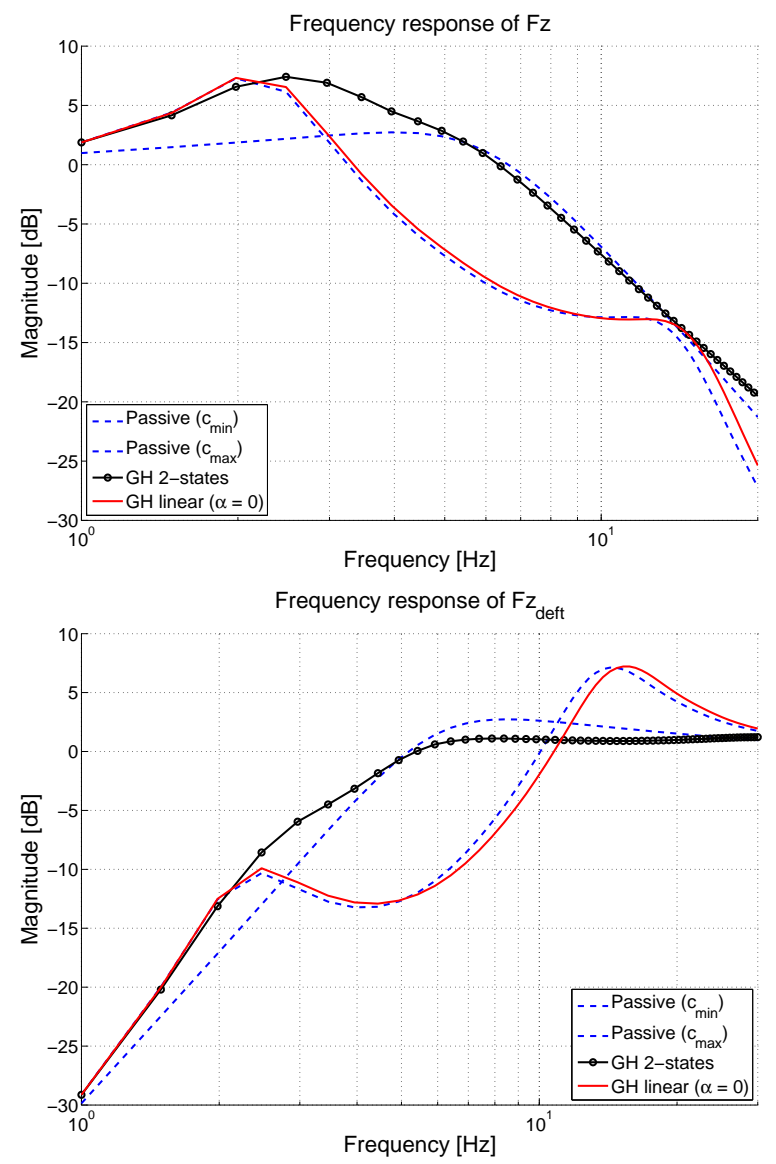

Fig. 4. Road-holding oriented control law frequency response $F_{z}$ (top) and $F_{z_{d e f_{t}}}$ (bottom).

the optimal bound, in dashed red) and (iii) emphasizes the interest of the flexible LPV semi-active rule, allowing to achieve good comfort performances (red left-oriented triangle) or road-holding ones (blue right-oriented triangle).

\section{CONCLUSIONS AND COMPLEXITY REMARKS}

In this paper we provide a benchmark of the main semiactive suspension control strategies. The proposed benchmark is of course not exhaustive but still quite large. We illustrate the interest of the recent dedicated semi-active suspension approach (such as SH-ADD), presenting a low complexity, while providing great comfort performances. Nevertheless, other approaches (such as LPV semi-active, or Hybrid MPC) shows some interests in the fact that they are quite flexible, but far more complex to adjust and implement. The proposed benchmark also include a complete evaluation of the passive suspension and the optimal performances such a system can achieve, and thus extends the results obtained in Poussot-Vassal et al. (2010).

\section{REFERENCES}

Ahmadian, M. and Reichert, B. (2001). System Nonlinearities Induced by Skyhook Dampers. Shock and Vibration, 8(2), 95-104.

Ahmadian, M., Song, X., and Southward, S. (2004). Nojerk skyhook control methods for semiactive suspensions. Transactions of the ASME, 126, 580-584. 

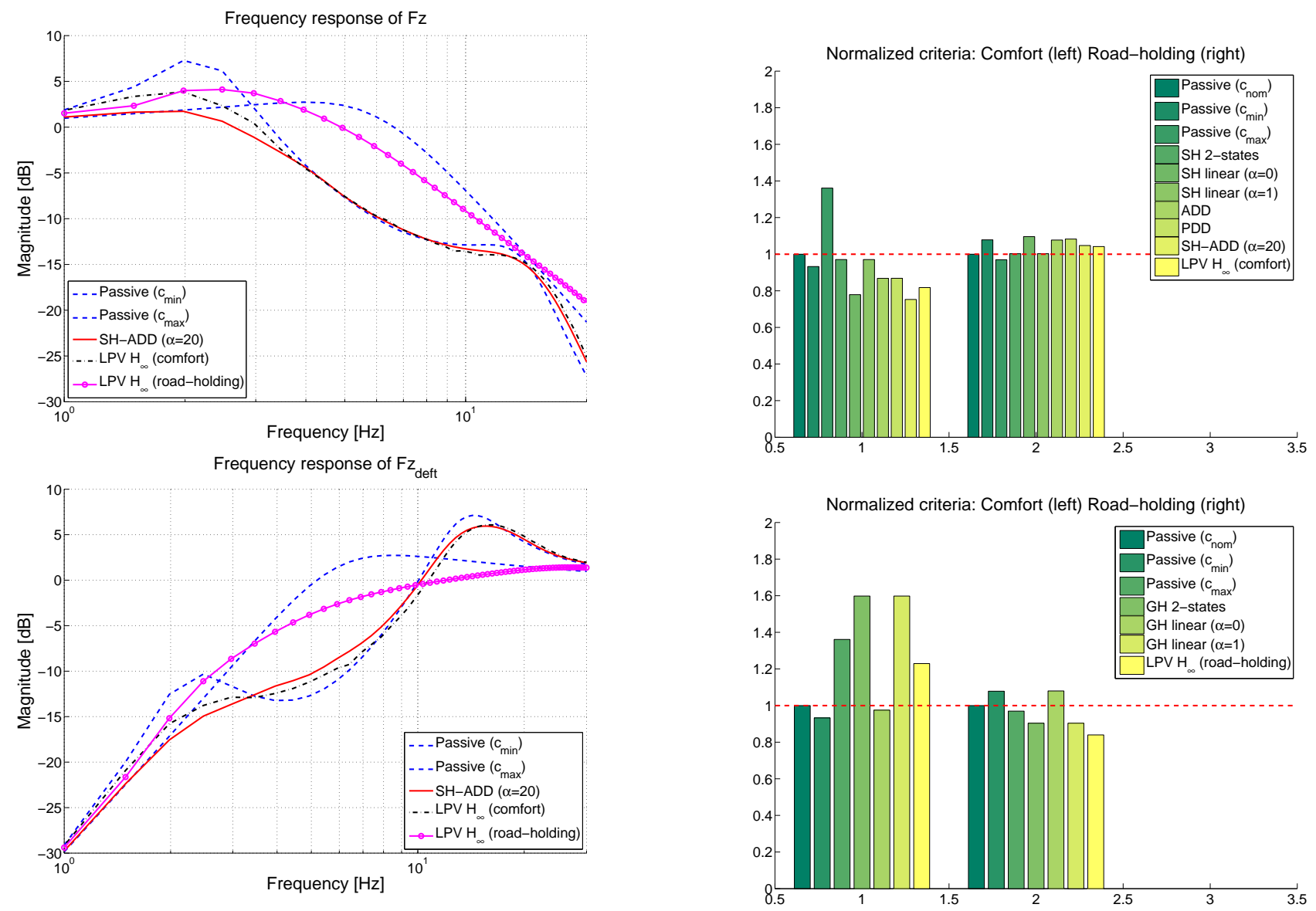

Fig. 5. Road-holding oriented control law frequency response $F_{z}$ (top) and $F_{z_{d e f_{t}}}$ (bottom).

Borrelli, F., Baotic, M., Bemporad, A., and Morari, M. (2003). An efficient algorithm for computing the state feedback optimal control law for discrete time hybrid systems. In Proceedings of the th IEEE American Control Conference (ACC). Denver, Colorado, USA.

Canale, M., Milanese, M., and Novara, C. (2006). Semiactive suspension control using fast model-predictive techniques. IEEE Transaction on Control System Technology, 14(6), 1034-1046.

Du, H., Sze, K.Y., and Lam, J. (2005). Semi-active $\mathcal{H}_{\infty}$ control with magneto-rheological dampers. Journal of Sound and Vibration, 283(3-5), 981-996.

Geurts, P., Ernst, D., and Wehenkel, L. (2006). Extremely randomized trees. Machine Learning, 63(1), 3-42.

Giorgetti, N., Bemporad, A., Tseng, H., and Hrovat, D. (2006a). Hybrid Model Predictive Control Application Toward Optimal Semi-active Suspension. International Journal of Control, 79(5), 521-533.

Giorgetti, N., Bemporad, A., Tseng, H., and Hrovat, D. (2006b). Hybrid model predictive control application toward optimal semi-active suspension. International Journal of Robust and Nonlinear Control, 79(5), 521533.

Giua, A., Melas, M., Seatzu, C., and Usai, G. (2004). Design of a Predictive Semiactive Suspension System. Vehicle System Dynamics, 41(4), 277-300.

Guardabassi, G. and Savaresi, S. (2001). Approximate Linearization via Feedback - an Overview. Automatica, $27(1), 1-15$.

Fig. 6. Normalized performance criteria comparison for different comfort (resp. road-holding) oriented control strategies. Comfort criteria - when cost function is $J_{c}$ (left histogram set) and Road-Holding criteria - when cost function is $J_{r h}$ (right histogram set).

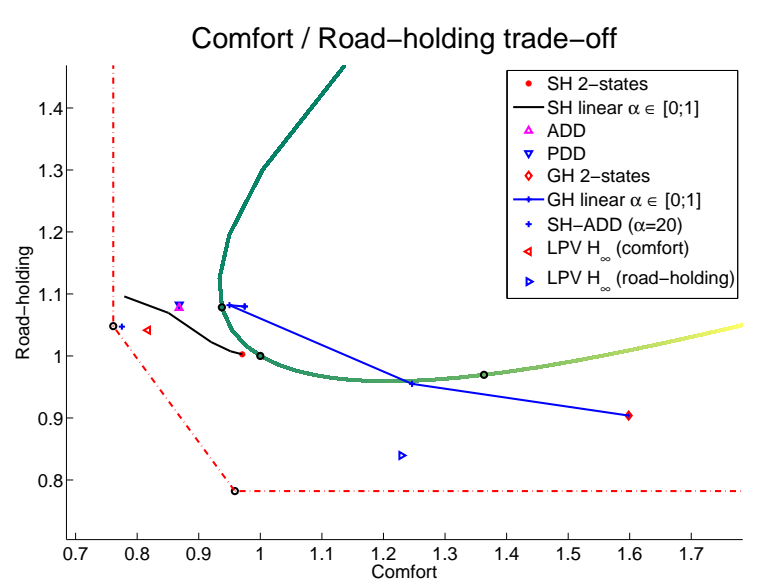

Fig. 7. Normalized performance criteria trade-off for the presented control algorithms, compared to the passive suspension system, with damping value $c \in$ $\left[c_{\min } ; c_{\max }\right]$ (solid line with varying color), optimal comfort and road-holding bounds (red dash dotted). 
Hong, K.S., Sohn, H.C., and Hedrick, J.K. (2002). Modified skyhook control of semi-active suspensions: A new model, gain scheduling, and hardware-in-the-loop tuning. ASME Journal of Dynamic Systems, Measurement, and Control, 124(1), 158-167.

Hrovat, D. (1997). Survey of advanced suspension developments and related optimal control application. Automatica, 33(10), 1781-1817.

Karnopp, D., Crosby, M., and Harwood, R. (1974). Vibration Control Using Semi-Active Force Generators. Journal of Engineering for Industry, 96, 619-626.

Karnopp, D. (1983). Active damping in road vehicle suspension systems. Vehicle System Dynamics, 12(6), $296-316$.

Kawabe, T., Isobe, O., Watanabe, Y., Hanba, S., and Miyasato, Y. (1998). New semi-active suspension controller design using quasi-linearization and frequency shaping. Control Engineering Practice, 6(10), 11831191.

Kiencke, U. and Nielsen, L. (2000). Automotive Control Systems. Springer-Verlag.

Margolis (1983). Semi-active control of wheel hop in ground vehicles. Vehicle System Dynamics, 12(6), 317330 .

Morselli, R. and Zanasi, R. (2008). Control of a port hamiltonian systems by dissipative devices and its application to improve the semi-active suspension behavior. Mechatronics, 18, 364-369.

Poussot-Vassal, C., Savaresi, S.M., Spelta, C., Sename, O., and Dugard, L. (2010). A Methodology for Optimal Semi-Active Suspension Systems Performance Evaluation. In Proceedings of the 49th Conference on Decision and Control. Atlanta, Georgia, USA.

Poussot-Vassal, C., Sename, O., Dugard, L., Gáspár, P., Szabó, Z., and Bokor, J. (2008). A New Semi-active Suspension Control Strategy Through LPV Technique. Control Engineering Practice, 16(12), 1519-1534.

Rossi, C. and Lucente, G. (2004). $\mathcal{H}_{\infty}$ control of automotive semi-active suspensions. In Proceedings of the 1 st IFAC Symposium on Advances in Automotive Control $(A A C)$. Salerno, Italy.

Sammier, D., Sename, O., and Dugard, L. (2003). Skyhook and $\mathcal{H}_{\infty}$ control of active vehicle suspensions: some practical aspects. Vehicle System Dynamics, 39(4), 279 308.

Savaresi, S.M., Poussot-Vassal, C., Spelta, C., Sename, O., and Dugard, L. (2010). Semi-Active Suspension Control Design for Vehicles. Butterworth Heinemann.

Savaresi, S., Siciliani, E., and Bittanti, S. (2005). Acceleration driven damper (ADD): an optimal control algorithm for comfort oriented semi-active suspensions. ASME Transactions: Journal of Dynamic Systems, Measurements and Control, 127(2), 218-229.

Savaresi, S. and Spelta, C. (2009). A single-sensor control strategy for semi-active suspensions. IEEE Transaction on Control System Technology, 17(1), 143-152.

Sename, O. and Dugard, L. (2003). Robust $\mathcal{H}_{\infty}$ control of quarter-car semi-active suspensions. In Proceedings of the European Control Conference (ECC). Cambridge, England.

Simon, D. (2001). An Investigation of the Effectiveness of Skyhook Suspensions for Controlling Roll Dynamics of Sport Utility Vehicles Using Magneto-Rheological
Dampers. Ph.D. thesis, Virginia Polytechnic Institute and State University.

Sohn, H., Hong, K., and Hedrick, J. (2000). Semi-active control of the macpherson suspension system: Harwarein-the-loop simulations. In IEEE CCA 2000, 982-987. Anchorage, Alaska.

Song, X., Ahmadian, M., and Southward, S. (2007). Analysis and strategy for superharmonics with semiactive suspension control systems. ASME Journal of Dynamic Systems, Measurement, and Control, 129, 795-803.

Tseng, H.E. and Hedrick, J. (1994). Semi-Active Control Laws - Optimal and Sub-Optimal. Vehicle System Dynamics, 23(1), 545-569.

Valasek, M., Kortum, W., Sika, Z., Magdolen, L., and Vaculin, O. (1998). Development of semi-active roadfriendly truck suspensions. Control Engineering Practice, 6(6), 735-744.

Zin, A., Sename, O., Gaspar, P., Dugard, L., and J.Bokor (2008). Robust LPV - $\mathcal{H}_{\infty}$ control for active suspensions with performance adaptation in view of global chassis control. Vehicle System Dynamics, 46(10), 889-912. 